\title{
A CASE OF LEFT HOMONYMOUS HEMTANOPSIA.
}

\author{
BY JOHN TURNER, M.B. (ABERD.) \\ Senior Assistant Medical Officer, Essex County Asylum.
}

Emma JoHnson, aged 54, a house-painter's wife, was admitted on July 5, 1889. She had a paralytic stroke four or five years ago. Duration of insanity said to be three weeks. First attack: Facts indicating insanity on the admission paper were :-Unable to say where she is or what she has been doing. Memory for recent events a blank. Bit the hand of a nurse and attempted to strike one of the other inmates of the union.

On admission.-Stout, dark haired woman, complexion rather dark. Loss of power in left arm and leg, and sensibility to pricking is diminished in the limbs of this side but equal for both sides of face. Is in a state of mania, restless and excited, especially when talked to. Says her name is "anything." That she has sold her rings to get bread with. That she lives on her rent. She has no money and her husband does no work. Good health.

July 8. - She is very helpless on account of the paralysis of left arm and leg. The arm is contractured and semiflexed at elbow, and flexed at wrist and fingers; left leg very slightly flexed at knee and fixed so that she cannot move it (anchylosed). She can lift both her legs off the bed, but with difficulty. Both plantar reflexes are absent, both knee jerks much exaggerated. Tendency to ankle clonus in left foot. Sensibility of left leg to pricking is almost nil, and much blunted and perverted in the right. Left leg cold, right warm. Both legs are marked extensively from the knees inclusive to feet with cicatrices of ulcers. Has some white cicatrices on her arms, especially the right, and the skin is darkened around. Chest healthy. She is very delusive; lies and talks to her daughter, who she says is up above her and swears a great deal. Said she walked a mile yesterday. Is in bed.

September 20.-Her pupils are unequal, the right being the larger, and remained so till she died. They do not react to light, 
and the right only accommodates for near objects. Tongue straight. When she smiles her mouth is drawn up on the left. Analgesia: Marked on both sides of face, chest, neck, arms, and legs. Ancesthesia: Some on the left side, none on the right upper extremity, none on either side of lower extremity that I can detect.

Localization of prick or touch.-Is generally seven or eight inches out on left side, less on the right (tested by telling ber to place her fingers on the spot that I prick), same for legs and arms (tells correctly how many times she is touched or pricked on legs); Mentally : Is very talkative, boisterious spirits as a rule, delusion that her husband visits her every night. During 1890 no marked signs to note. As a rule is very cheerful and easily aroused to boisterous mirth. Sits quietly all day. Vomited one night in August.

March 20, 1891.-In a state of secondary dementia, dirty in habits and helpless. Grins and laughs when spoken to.

June 20.-She is stout and looking very well. Very talkative; will sit and talk to another patient who is not taking the slightest notice of her. Laughs frequently; excitable and irritable, and uses filthy language.

August 24. - She cannot walk without assistance. Protrudes tongue to left. She is quite unaware when I prick her on the left side of face or left hand, but calls out directly I do so on the right, or on either leg. She keeps chattering and laughing, but is very obstinate, and when asked to do anything replies as a rule "I shan't." Does not seem able to fix her attention on anything for long together. She does not appear deaf. She can see with either eye, will tell the time, grasp pennies held before her without any hesitation, and count them correctly. Always called the sovereign I was testing her with, half-a-sovereign. There is no doubt that the left half of each field of vision is blind, but not I think quite up to fixation line. It is impossible to test her with any great precision, as she will not fix her eyes on any object sufficiently long together, and when I held up a little piece of paper on the end of a pencil she took no notice of it, but she immediately grasped at a penny held on her right side, but took no notice of one on her left until it nearly approached the middle line.

August 28.-Tested again to-day for hemiopia. When she is talking to me and looking straight at me, if I hold up a half-crown on either side of her about three inches apart from one another, between her and me and equally far from the middle line, and ask her what she sees, she will reply " a shilling," and will put up her hand to catch hold of the one on her right. She does not perceive 
the other till I move it past fixation point, and then she grasps it without hesitation. Each eye was tested separately with similar results.

In September she was confined to bed with erysipelas of face, started probably from an injury-a blow to eye. Vomited several times during this illness. Her temperature rose to $104^{\circ} \mathrm{F}$., but in the course of a few days fell to normal again.

In December she fell out of bed and fractured her left clavicle, but seems to suffer no pain from the injury or examination.

March 10, 1892.- She ate a quantity of soap this morning and her lips are much swollen. She has done this once before. Sits talking and laughing to herself and other patients.

May 18.-Is confined to bed, where she lies huddled up on her left side. Her left foot and lower part of leg is swollen and the instep is ulcerated.

June 3.-C'Tested for hemiopia again to-day with similar results. Slight superficial sore on left buttock; speaks and knows what I say.

June 10.-Abscess formed over sacrum which has burst.

June 21.-Enormous hard brawny swelling of right parotid. Superficial sore about size of five shillings on left hip.

June 24.-To-day she died.

Post-mortem five hours after death.

Body.-Thin, rigor mortis present. Sores: Slight superficial one on left hip, and some very slight superficial abraded spots about inner aspect of left knee, right hip and right foot. Hard swelling of right parotid.

Atrophy of left arm and leg; there was about an inch difference in the circumference of arm, forearm, and thigh; no shortening.

Head.-Scalp thick.

Skull of average thickness and density, deeply grooved for blood vessels internally, no deeply marked pacchionian depressions.

Dura-mater firmly adherent to skull over the posterior part of the superior longitudinal sinus, which latter contained a little dark clot easily removed.

Arachnoid.-A bath of lymph having a jelly-like aspect was seen to cover the whole vertex beneath the arachnoid. There were deeper lakelets over the posterior end of the two lower frontal convolutions and lower end of ascending frontal on either side, and also over each superior parietal lobe, but deeper on the right. The arachnoid was opaque and thickened. Meninges not adherent to cortex. 
Circle of Willis abnormal, there did not appear to be any posterior connecting vessel on the right side. The vessels were generally small and slightly atheromatous.

Cerebrum.--There was atrophy of the whole cerebrum, but more pronounced on the right, especially in the right præ-frontal lobe and the tips of both temporal lobes. A portion of the second occipital convolution on the right had a shrivelled appearance contrasting very markedly with the similar convolution on the left (see fig. 1). Brain firm and tough.

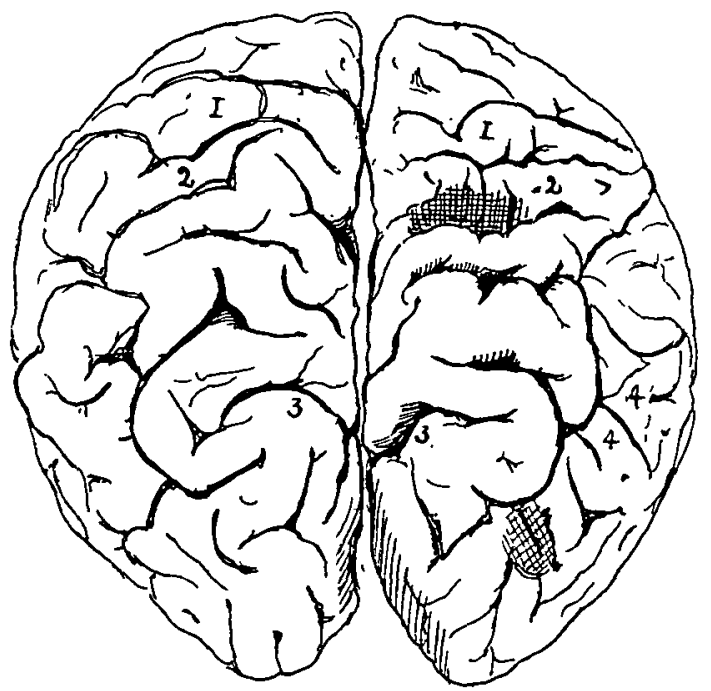

FIG. 1.

1. Is placed on ascending frontal convolution.

3. Is adjacent to the parieto-occipital fissure.

4.4. Placed on angular gyrus.

The cross-shaded parts represent the seat of the lesion in the ascending parietal and adjacent superior parietal convolutions; and also the atrophied convolution in the second occipital gyrus.

The figure is outlined from a photograph taken of the brain.

Small cortical lesions in right hemisphere-old hæmorrhagic softenings.

(1) About the size of a pea in the back part of superior frontal.

(2) A rather large lesion implicating the upper part of ascending parietal and adjacent superior parietal lobe.

(3) A lesion in the second occipital convolution (see fig. 2). This lesion existed as a small irregular cyst situated at the junc- 
tion of the cortex and white matter, and from it extended a degenerated tract running downwards and forwards beneath the posterior horn of the lateral ventricle for a distance of 6.5 centimetres. This tract occupied the lower most part of the optic radiations (see figs. 2 and 3 ).

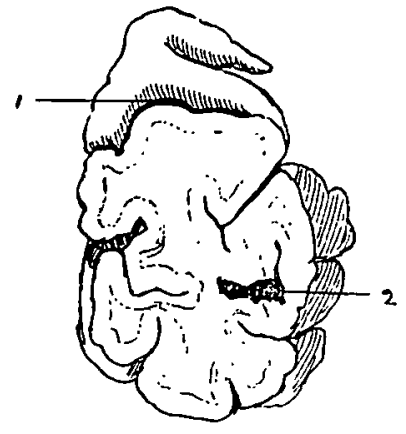

FiG. 2.

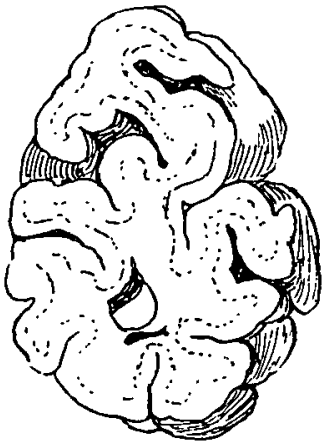

FIG. 3.

Horizontal section through parietal occipital fissure.

1. Parietal occipital fissure.

2. Small cyst.

Both figures are outlined from photographs.

Lateral ventricles enormously distended with fluid. Small granulations on the lining membranes at the anterior ends; softened patch (old hæmorrhagic focus) observed on surface of left caudate nucleus about an inch from anterior end; this was seen on the floor of the ventricle.

Both optic thalami appeared shrunken but the right was the more atrophied of the two.

I'ransverse vertical sections made at distance of one centimetre from each other revealed numerous softened patches in the white matter of each præfrontal lobe and for a large extent below the right ascending parietal and right superior parietal lobes. Small softened patches also iu right lenticular nucleus. The extent of the lesion in the occipital lobe has been referred to.

Right crus cerebri smaller than left. In the hardened preparation there was a difference of three millimetres in greatest length.

Right half of pons flattened, and the motor tracts on right side much smaller than on the left.

Right pyramid of medulla oblongata smaller than left.

Floor of fourth ventricle studded with coarse granulations.

No lesions observed in cerebellum. 
Weight of fresh brain :-

Right cerebral hemisphere (stript) ... 313 grammes.

Left

drachnoid and $\mathrm{Pia}$ "

" $\quad 340 \quad$,

Pons and Corpora Quadrigemina .. 21 ",

Cerebellum

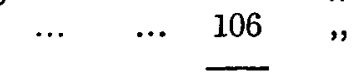

$$
\text { Total ‥ } 794 \text {, }
$$

Eleven and a half ounces ( $327 \mathrm{cc}$.) of fluid collected from base beneath membranes and from ventricles.

Thorax.-Small patch of pneumonia at base of right lung. Heart weighed 227 grammes.

Abdomen.-Liver 1297 grammes, right kidney 113 grammes, left kidney 99 grammes.

This case is of interest, inasmuch as it presents a strictly limited and small lesion of a portion of the cortex and white matter in a region of the brain concerning whose function considerable difference of opinion still exists.

Briefly summarized there was with the small occipital lesion well-marked and persistent left homonymous hemianopsia, although neither the cuneus or the angular gyrus were involved.

Unfortunately the mental condition of the patient was such that a more precise account of the visual defects could not be obtained; it was impossible to accurately define the limits of the hemianopsia, although there was little doubt but that it reached up to fixation point, nor was it possible to test her for color hemiopia, \&c. 